\title{
THE ROLE OF UNIVERSITIES IN LOCAL DEVELOPMENT
}

\author{
BRUNO DALLAGO
}

\begin{abstract}
The paper deals with the role that universities can have in promoting innovation in general and at local and regional level in particular. In doing this, the nature of universities and the quality of their relations to industry and governments is of paramount importance. During the last three decades university-industry relationships and the supportive role of governments moved from more general, upstream approaches in line with the traditional public role of universities to more specific, downstream focused approaches. The latter approaches lead to universities playing directly an economically useful role. This move is complementary to the move in the dominant relationship between universities and industry from large transnational companies and few large and prestigious universities to mostly small and medium size enterprises and regional universities. Universities contribution to local development is thus increasingly important, although not without dangers for the integrity of universities. Yet it turns out that producing knowledge is not enough and also the absorptive capacity of the local context and its actors is necessary. The concept of learning regions is aimed to stress this relationship and is therefore particularly useful and productive to analyze and understand the role of universities in innovation.
\end{abstract}

Keywords Local development, Universities, Knowledge, Innovation, Governments, Europe, United States, Learning organizations

1 University of Trento, Department of Sociology and Social Research; e-mail: bruno.dallago@ unitn.it. The paper was presented at the international conference on "Regional Competitiveness: Governance, Knowledge, Changes", Sapientia University, Miercurea Ciuc/Csíkszereda, 25-26 October 2013. I thank the participants to the conference and two anonymous referees of CJSSP for helpful comments on an earlier version of this paper. 


\section{INTRODUCTION: THE STATE OF EUROPE AND INNOVATION}

The last decades have witnessed a general slowdown of productivity in EU countries, particularly compared to emerging economies and in spite of productivity convergence of new member countries to the EU average. This general picture is complemented by decreasing interregional inequalities and increasing inter-country differences in old member countries and increasing inequalities within new member countries. However, in the latter case intercountry differences have decreased, also thanks to the massive re-orientation of EU support for regional development in favor of new member countries.

The EU is also losing the innovation and competitiveness race compared to its most important competitors (Sonderman 2012), in spite of the ambitious plans of the doomed Lisbon strategy and the new Europe 2020 strategy. The most important competitors include the United States, Japan, South Korea and Switzerland. The EU still maintains a clear lead over emerging economies, but China is catching up quickly.

This conclusion refers to both countries and regions. Most EU member countries, including all new member countries of Central and Eastern Europe, are moderate and modest innovators (EU 2012). The same refers to all regions in the new member countries (with the only exception of Prague) and an important part of the regions in old member countries (Hollanders et al. 2009). The innovation leaders in the European Union are the countries and the regions of Northern Europe (Sweden, Germany, Denmark and Finland, EU 2013).

Comparisons of countries and regions show a considerable variety and variance of situations both among countries and among regions. The same observation holds if we look at industries in international comparison. A recent EU report on ICT industries (Forge et al. 2013, p. 3) observes that “... rather than there being a simple innovation gap with the EU lagging behind the USA, a more nuanced picture emerges in which firms in different countries have strengths in different sub-sectors and in different parts of the value chain."

A further important contribution to this dismal picture of Europe comes from the controversial management of the present crisis, which sees the EU, and particularly the Eurozone performance falling behind all other developed and emerging economies'. Failing competitiveness, together with drawbacks in the field of innovation are serious problems in the European Union. It is not so clear whether they are actual problems of the European Union. They are serious problems in most EU member countries, but not all. Northern 
countries clearly appear to be successful. Yet most other countries not only are not successful: they are falling behind, as much as most of European regions are witnessing.

The EU is aware of the importance that universities should have for the development of countries and regions. In this it is complemented by other European bodies, such as the European University Association, that are trying to upgrade and strengthen the role and quality of European universities. To this purpose the EU has financed the E3M project (European Indicators and Ranking Methodology for University Third Mission) whose aim is to identify, measure, and compare so-called third mission activities of universities (Green Paper 2012, http://e3mproject.eu). Third mission undertakings are a set of accomplishments that universities are increasingly engaged in, along with the traditional activities of education and research. Third mission undertakings include life-long learning, technology transfer and innovation, and social engagement. The main goal of the E3M project is to create a set of standardized indicators on Third Mission activities and related methodology by means of which the performance of universities can be measured and ranked. Measurement takes place along three dimensions: life-long learning, technology transfer and innovation, and social engagement.

In this paper I concentrate on one aspect of the role of universities that scholars and observers unanimously consider to be fundamental: the role of universities and research in promoting the innovation and competitiveness of countries and regions. For instance, the EU report on ICT industries quoted above stresses that "[a] key lesson from the analysis of the three subsectors is the critical importance of higher education, particularly elite university research, and of local networks as generated by clusters." (Forge et al. 2013, p. 9) The report conclusions on the case studies include that "successful innovation depends to some extent on excellence in education and strong and active links between knowledge generation, knowledge exchange and knowledge exploitation (i.e. between universities and firms)." The US showed the way in this type of development. Other important requisites for successful innovation include creating an innovation friendly environment and having the public sector providing important financial and non-financial support, including cluster-generating policies. Unfortunately "The research performance of Europe's universities seem to lag behind that of their US counterparts..." (p. 45). This observation in turn leads the authors to stress the fundamental role of governments.

Being most universities local and regional players, with only a handful of them being world players, the contribution of universities is central to the success of regions and, through this, of countries and the EU. It is therefore 
particularly important to look at the relation that exists between universities, enterprises and sub-national governments.

It appears from the study of the successful cases of Northern Europe and the United States (and apparently the same refers to China) that what makes these countries and their regions successful is the capability of fostering a systemic approach to innovation which gives universities and research a central role, together with governments and business. This does not appear to be the general case of Southern and Eastern EU member countries. This inability to have a systemic approach to innovation and competitiveness in most of the European Union - at both regional, national and inter-country level - represents a structural problem in the process of integration, a problem that the EU reaction to the international economic crisis has only exacerbated.

In most of Europe enterprises, governments and universities find hard to cooperate and coordinate their action and activity and universities haven't been particularly successful in establishing interregional and inter-country knowledge and research networks, in spite of EU programs and support. Universities are still largely funded through public resources and fiscal rules hardly stimulate enterprises to finance universities. Public financing is still largely implemented through administrative approaches and in most countries universities are financed after the number of enrolled students or the number of teachers, with hardly any important role for outcomes. The European adaptation to the international economic crisis has magnified these features and led to severe and sometimes massive cuts of financing to universities. At the same time the recognition of degrees within the European Union still finds limits that obstacle the integration of the high levels of the labor and skill markets. It is therefore fundamental to understand which role universities could play in the development process.

In the following I shall concentrate on the role that universities can have in promoting innovation in general and at local and regional level in particular. I shall look at both successful experiences, particularly of the United States, and more general explanations, looking at the conditions for successful outcomes. The next section is devoted to illustrate the contribution of universities to economic development. The example of the United States appears useful and illuminating in various senses: section three looks particularly at the interaction among universities, industry and governments in that country. The role of knowledge, innovation and competitiveness is discussed in section four by looking at who and how produces them. Section five goes down to the local level and considers that producing knowledge is not enough and also absorptive capacity is necessary. The concept of learning regions is aimed to stress this relationship and is therefore particularly useful and productive 
to analyze and understand the role of universities in innovation. Section six concludes.

\section{THE CONTRIBUTION OF UNIVERSITIES TO ECONOMIC DEVELOPMENT}

In the globalized world economy competition makes more difficult for firms to control the outcome of their investment in R\&D and requires risk diversification. Adaptation to such structural context change includes strengthening the international institutional framework for the protection of investment (particularly the role of the WTO and other UN institutions, and patents) and the "outsourcing" by firms of research activity to external agencies, of which universities are particularly important. In this way universities assume a useful economic role in development. In a sense, this is a return to the nineteenth-century paradigm of social usefulness (Pavitt (2003).

Innovation is largely a territorial process. The territorial nature of innovation derives from the fact that innovation is increasingly distributed among different organizations connected through the central role of proximity. There are different reasons why this is so, which include technological, economic and social processes (Lawton Smith 2006). All recall the central importance of proximity.

In the technological perspective, locating firms close to universities is important for gaining faster and easier access to the latest research finding. The effect is particularly strong in technologically advanced branches if there is a close match between researchers and engineers in firms and in universities, a fact that advantages large multinational firms over small and medium size firms. More mature industries also have extensive links with universities, but these links tend to be more short-term.

Economic explanations look primarily at agglomeration and scale economies. Agglomeration economies derive from the fact that the cost that each firm has to afford in order to cooperate with a university is lowered when other firms are pursuing the same approach since this allow each firm to share the costs. Agglomeration and the proximity that is thus established create important spillovers in the form of flows of knowledge that accrue to organizations and individuals. Such spillovers, that as a rule are different through industries and not constant over time and often transitory, are from universities to firms but also are created among firms that are located in the same territory. Scale economies derive from the increasing returns to scale that 
urbanization makes possible. However, other studies found that the location of industrial innovation depends largely upon firm-internal linkages between production and R\&D while the role of universities is marginal (Tecu 2013).

Social explanations are mostly based on the role of tacit knowledge and social interaction that localization makes possible. The importance of tacit knowledge in innovation processes requires that producers and utilizers of knowledge in different organisations share direct, personal contacts. These contacts, when non episodic, build up networks of what Granovetter (1973) named 'weak ties'. Their main advantage over more stable strong ties lies exactly in the support they give to the flow of information and knowledge. Weak, multiple ties among people expert in different aspect of innovation and active in different organisations - universities and firms - are embedded within particular locations.

Florida (1005a, 2005b, 2006, Florida et al. 2006) offers an interesting explanation of the role of universities, an explanation which is linked to his creative class idea. In his view of economic growth, it is the so-called creative sector that plays the fundamental role. The creative sector, which employs approximately one-third of total employment in the United States, includes science, technology, design and all other applications of creativity such as art. In the creative economy the driving forces of economic growth are technology, talent and tolerance (the 3Ts). The originality of the creative economy approach lies in that it considers two of the traditional economic explanations, technology and talent (similar to but not identical with human capital) as flows that are captured through tolerance. Tolerance, which is defined as the openness of a place to new ideas and new people, plays the fundamental role in attracting the widest pool of creative talent. The concentration of creative people in one place gives this place what Florida defines as "enormous economic leverage" or productivity advantage.

Universities in the creative economy become increasingly important for innovation and the economic growth of the territories. They are centres for the generation of research and new technologies and for the production and attraction of talent. Yet they play a fundamental role in the establishment of the third component: openness and tolerance in the local milieu. To take advantage of the role of universities, territories require an absorptive capacity, namely the capacity to attract, learn and utilize the innovation and the capabilities that universities generate. Thus, in order to play a propulsive role in the local economy and society universities must organically integrate in the local creative system.

Although it is difficult to quantify the contribution of university research and education to economic development, scholars and international agencies have 
found that that contribution is important, although dependent upon various important factors. While trying to enhance their contribution to economic and social development, universities have also contributed in important ways, sometimes to a sizeable extent, to improve their own financial situation and social importance. Such outcome has provided the resources for advancing strategic and frontier research also in fields not directly related to their economic and social role (Geiger and Sá 2008).

Research universities have to afford and be successful in pursuing a dual goal: generate inventions and solutions and make sure that those inventions and solutions are transferred to developers, be they private firms and other kinds of organizations or public institutions. This may include a host of activities: from patenting and licensing to spin-offs and commissioned research, from advising to promoting and developing academic fields and subjects that contribute to knowledge and technological progress. Clearly these diverse goals require different academic policies and internal organizational set ups. They also require different public policies, be they at national and even international level or at local level.

One important aspect to be considered is that the public and private concern with innovation and the important contribution of research and universities to it has led not only to offer substantial amounts of public and private resources to that end. This concern also led to set up systems for controlling and evaluating the outcome of the use of those resources. This in turn has generated a substantial amount of transaction costs and reporting intricacies linked to the use of those resources which has favored a low number of large, well organized and rich universities and a relatively low number of specialized top researchers to the disadvantage of other universities and researchers. Although this may have the advantages of scale economies and spillovers in research activity and evaluation, it has also disadvantages in terms of variety. Given low numbers and the fact that, although competing, these researchers are mostly in strict contact among themselves run the danger of limiting the pool of ideas and approaches and ending up in scientific conformism. Further to this we must remind that most of research funds and discoveries are in a low number of so-called strategic sciences and science-based technologies, particularly biotechnology and molecular biology, nanotechnology and pharmaceuticals.

One further important problem concerns the approach of public and private sponsors and their relation to universities. The problem with private sponsors is that they may constrain directly or indirectly the academic freedom of researchers and thus the development of alternative fields and paths of scientific development. According to many observers and scholars who 
researched the problem this is not a real risk and perhaps the opposite is true. Commissioned research, a highly competitive field, provides the incentives and the resources to develop other fields, including other unrelated fields and basic research. Universities which have additional resources from industry may allocate a greater part of other resources to fields that increase the prestige of the university and its scientific standard, both necessary conditions to obtain private financing. But again this may be true for few, large worldclass universities. It is not necessarily true for other universities.

The danger of a rent-seeking attitude by universities is potentially a serious issue, particularly in the allocation of public financing. This happens when large influential universities are successful in convincing agencies and governments to allocate funds to the fields and subjects where these same universities are strong. This could reduce the contestability of research subjects, thus restricting variety and research innovation.

Indeed, behind the economic relevance of research and science there are various dangers. These descend from the quality of governments' science and research policies and the incentives that governments, particularly local and regional governments have in devising and implementing those policies. In general, it is considered that national and international agencies and national governments have positively contributed to the development of frontier sciences and of science-based technologies (Geiger and Sá 2008).

Different is the landscape when sub-national governments are considered. Policies are often poorly designed, their knowledge and view of scientific and technological issues are approximate, not up-to-date and based on questionable economic assumptions. These problems may descend from the unpreparedness of these governments and their thin technical and scientific/ intellectual basis. However, there is more than that: subnational governments must make sure that the effect of their policies goes to the advantage of their region, an issue that is of no or lesser concern for national governments and irrelevant for international agencies.

Four aspects are important in assessing the consequences of science-based technologies on the internal structure and public role of universities. First is the relation between universities' pursue of economic relevance, which is eminently private in goals and limited to few sciences and fields (although these aspects may be less important when the promoter and supporter is a public agency) and the universities' mission, which is eminently public.

Second, this role of universities has required a transformation of their internal organisation. In particular, universities had to set up offices and structures and hire qualified personnel to promote the relation with industry and public institutions and to market the outcome of research, including through spin- 
offs. This has often created problems due to the uneasy integration of these offices in the structure of universities. In any case, such offices are mainly oriented towards small and medium size initiatives and enterprises.

Third, science-based technologies are eminently interdisciplinary while the traditional structure of universities is based on distinct disciplines. Pursuing science-based technologies and the economic relevance of research requires that structures and programs are set up for integrating different disciplines and fields of research. Other important issues are hiring and, if necessary, training specialized personnel, formulate new strategies for hiring faculty and set up research institutes with external support and perhaps the participation of the external sponsors' representatives in the governance of these institutes. One further aspect is that much of frontier research takes place within the laboratories of large corporations by researchers who are employees of the corporation. In fact, these research activities present many company-specific idiosyncrasies and universities are perhaps ill equipped for the most applied aspects and marketing-focused innovation. For this reason the prevalent relations between universities and industry is one of long-term relations on background topics, to which commercialization of the findings of research through university spill-overs offer an important complementarity.

Fourth, secrecy of findings and discoveries is often a precondition for participation in science-based technologies, particularly when the promoter and sponsor is a private organization. This is contrary to the universities' mission and the professors' and researchers' view that research should lead to public results. The public character of research within universities finds a strong correspondence in the way in which university careers are managed, i.e. through publications, conferences and other means of circulating the findings of research.

The bottom line is mixed. Pursuing economic relevance and participating in science-based technologies made their way through universities and have had important consequences all over the world, although with different intensity in different countries and regions. They have transformed universities and helped the development of economies and societies. Yet the contribution of universities appears still rather modest and undeveloped compared to the possibilities and needs that exist. 


\section{UNIVERSITIES AND LOCAL ECONOMIES AND GOVERNMENTS}

The United States experience confirms the above findings on the contribution of universities to local development and offer a useful benchmark. In fact, the country initiated and devoted most strength to policies and public support for technology-based economic development (TBED), initially as a component of its effort in the military and space competition with the Soviet Union. Substantial differences exist between federal and state policies. Federal agencies took the initiative by creating incentives for universities and firms to collaborate. Their goal is general and not linked to retaining tangible benefits within particular regions. The latter is a major concern for state policies. Consequently, the states' TBED policies are more leaned toward the smaller technology-based firms. (Geiger and Sá 2008)

Two main approaches of state policies can be identified, with substantially different consequences for universities. What has being termed 'upstream' policies (Geiger and Sá 2008) consist of long-term strategies which aim at complementing the R\&D of existing high-tech industry and fostering new industries. These policies are usually particularly beneficial to universities. Indeed, they tend to strengthen the research capacity of universities through infrastructure, strategic faculty hiring, graduate education, or other forms of targeted support.

The second approach is that of 'downstream' policies and programs assisting the advancement of new technologies into marketable innovations. This is a shorter-term approach that aims at creating new and nascent technology firms and creates jobs through the success of these firms. This kind of policies provide universities with less direct benefits, which include assisting the development of spin-off firms.

Upstream policies were dominant during the 1980s, but outcomes were rather disappointing, so that during the following decade states turned mostly to downstream policies. It is difficult to strike a balance of the usefulness and success of science and technology policies of the states. These can be divided into short-term and long-term outcomes for the economy and outcomes for universities. In the short-term, spending for research or other forms of support to universities produces a multiplier effect as in the case of other forms of economic activity. According to a study prepared by the University of Arizona each dollar spent for research generated and additional $\$ 1.35$ in sales and $\$ 0.87$ in wages. (Geiger and Sá 2008, pp. 111-112) In the long-run, support to universities is extremely difficult to measure, since it is a support focused on a limited part of the economy upon which many other factors have important effects. 
Clearer are the consequences for universities whose set up, endowment with human and technological resources, and performance are undoubtedly strengthened. However, most policies directly or indirectly also produce different types of valuable outputs, in particular knowledge and human capital. These are outcomes that is very difficult to measure. Moreover, both are highly mobile. Finally, it is important to stress that the positive effect for universities notwithstanding, the ability of regional industry to benefit from knowledge and human capital that local universities produce depends on the absorptive capacity of the local economy. In this, it is particularly mature industrial clusters that are more effective in utilizing human capital.

The organizational structure of most universities continues to reflect the traditional model based on single disciplines and of small-scale investigation. Thus the role of universities in the new vision of economic development poses the constant challenge of balancing the disciplinary orientation of academic departments with the multidisciplinary and problem-oriented approach that is required in the relation with industry.

Universities usually set up centers and institutes to this latter purpose. This solution has proved important also for accommodating the requests and needs of regional development. However, academic careers and institutional reputation continue to depend largely upon academic disciplines. This situation may create an uneasy relation among different components of the universities' structure.

It is important to highlight that there exists a highly differentiated situation in this field. Not all universities are the same and play the same role and similar observations hold for governments and for industries and firms. First, the traditional public role of universities in both education and research remains invaluable also for industry. Indeed, industry makes extensive use of both these functions and, in the United States, supports them financially.

Second, industry has a interest in hiring graduates: this is perhaps the most effective way to create an environment within the firms and the people for pursuing innovation and firms have a keen interest in maintaining links with universities. Indeed, according to Lawton Smith (2006, p.6), “...far too much attention has been paid to the contribution universities make to economic development such as spin-offs, patents and licensing as means for technology transfer, and ... insufficient attention has been paid both in Europe and in the US to the contribution of universities to local and regional labor markets, through graduated students ...'

Involvement of universities, or at least a minority of them, in frontier research on behalf or together with large companies is a third important component, but has its own limits. This involvement can be done in two 
ways: by establishing laboratories in the proximity of universities thus building up a permanent relationship which involves a substantial amount of company control; and by entering into long-term agreements with University laboratories. Clearly, the former solution tends to involve a limited number of large corporations and few large and prestigious universities. Needless to say, both take a risk in entering such a partnership that, by its nature, must be long-run if it wants to be successful.

More interesting is, in the perspective of local development, a fourth type of university- industry relation. This is the contribution of universities, most of them universities of regional relevance, to small-scale innovation. The latter involves primarily small and medium size enterprises and includes university spin-offs. In this kind of relation patents and licences are important for allowing firms to develop a university discovery into commercial products.

This is perhaps the most distinct contribution that universities give to economic development and, within it, to local development. Many of these enterprises would not exist without the university contribution. The Association of University Technology Managers (AUTM) reports that in the United States universities had 38,600 active licenses with 3,927 operating start-up companies and introduced 591 new products in 2010. These initiatives generated \$2.4 billion total income in 2010 compared to $\$ 59.1$ billion total research expenditures. The contribution of university licensing to university financing is quantitatively rather modest. However, these initiatives are strategic for the development of certain fields and for the regions surrounding universities. (www.autm.net/AM/Template.cfm?Section=FY_2010_Licensing_Survey\& Template $=/ C M /$ ContentDisplay.. fm $\&$ ContentIID $=687 \overline{4}$ downloaded on 18 October 2013).

These kinds of initiatives, however, and the university-industry relation they require are intrinsically delicate. Most university inventions are embryonic when seen from the perspective of their marketability. They may represent an excessive risk, that is not possible to evaluate at this early stage, for venture capital and perhaps even for business angels, and they must rely on the inventor's tacit knowledge. Most often the solution is seed capital that universities themselves offer to their researchers through faculty start-ups, together with special laboratory space. Universities are increasingly giving up returns in the form of licensing revenues in favor of equity in the relevant projects.

These kinds of developments require a rather deep transformation of the universities internal structure. According to the US experience, two foremost transformations should be mentioned. First is the establishment of a technology transfer office in charge of handling intellectual property. 
The experiences gathered so far, though, have been rather disappointing. A part a few exceptions, the productivity of these offices have been poor. Second is the establishment of large laboratories focused on technologies deriving from research frontier. These laboratories create a space where university researchers can interact with industry developers. This helps to translate the invention into an innovation. The role of states is especially important: states see important implications for their territory and provide most resources. These developments show that, along with important yet problematic philosophical and practical problems, economic relevance offers also the interesting perspective of being a complement to the traditional role and mission of universities more than an impediment.

The inherent risk in early-stage discoveries and the critical role of the inventor often frighten large companies and opens important room for small firms and strongly influences the market for university patents. Indeed small firms are often the only firms willing to take on higher risk: in 2004 they took $70 \%$ of licenses of universities (Geiger and Sá 2008, p. 38). Small firms are not scared by the pursue of radical technologies that might jeopardize existing products or processes. This offers important opportunities for local development.

It must be recognized, however, that the role of universities in fostering clusters and promoting directly economic growth is very limited. It is also worth to note that the effect of their research and inventions on the territory depends largely upon a receptive and active context and in particular on the existence of a diffused economic culture and of entrepreneurs who are willing and capable to transform those technologies into successful economic activity.

While large companies tend to disperse their collaboration with universities on large territories and even worldwide, small enterprises are in a sense logical partners of regional universities. This has to do in part with the nature of much relevant research at regional universities and with the role of proximity. Proximity is particularly important in the case of applied research, when the continuous contact and interaction between the researcher inventor and the developer producer is fundamental.

\section{KNOWLEDGE AND INNOVATION AS PRODUCTION PROCESSES}

As theories of endogenous growth and a host of applied analyses have demonstrated, knowledge and innovation have a central role in the competitiveness and consequently the performance of countries and regions. 
Universities are fundamental in the production, transmission, and circulation of knowledge and in innovation through teaching, research, and different forms of transmission of their results, including consultancy and other forms of cooperation with firms.

The previous sections have demonstrated that universities are important to promote innovation also at local level. However, they are not enough. The capabilities and ability of regions and their constituencies (particularly governments, organizations, civic society) to demand, absorb, transform and adapt to the knowledge and innovation that universities produce constitute the other necessary side of the innovation and competitiveness process.

Absorptive capacity refers to "...the capacity to absorb and to adapt external knowledge to the local entrepreneurial context and thus transform it into higher productivity and innovation." (Asheim and Parrilli 2012b, p. 10). This process consists often of acquiring, appropriating, interpreting and adapting codified knowledge that universities and research centers generate and knowledge that flows from other enterprises and territories (Langlois 2003, Jensen et al. 2007).

Learning processes thus represent the software that puts the two hardware components of firms and universities into contact, supports mutual understanding and cooperation in successful production. Such learning requires individual and organizational effort, institutional support frameworks, organizational and workplace cooperation, incentives to change and innovation, ability to interpret and contextualize, sufficiently long time horizons and also a common language for communication or at least a good translation from one language, that of researchers, into the other language, those of entrepreneurs, technicians and workers. The greater the gap between the two hardware, the more important is the process of learning. Successful learning, particularly in disadvantaged cases, can be helped by means of different devices, including various forms of university-firm cooperation.

The concept of the 'learning organization' offers a rather new perspective. The concept was introduced some two decades ago by, among others, Richard Florida. Florida (1995) stressed that regions are becoming focal points for knowledge creation and learning and they function as collectors and repositories of knowledge and ideas. They also provide the underlying context which facilitates the flow of knowledge, ideas and learning.

The concept has been recently worked out to highlight the fundamental features and working that an organization needs in order to successfully manage learning process. This refers primarily to “...new forms to organizing work within a firm, such as self-determined and auto-organized work targets and work pace, continuous on-the-job training, and multi-function and 
multidisciplinary team work" (Asheim and Parrilli 2012b, p. 14). Learning organizations master different types of knowledge. Along with the traditional knowledge that results from $\mathrm{R} \& \mathrm{D}$, and important interactive and tacit forms of knowledge exchange.

The development of learning organizations requires a proper structure of the production and work process within the firm; proper incentives to the employees combining support to commitment and change, organizational flexibility, but also job and income security to those who may take up risks for pushing innovation through. Such developments greatly profit from a system of organizational and social welfare in line with 'flexible security' that various successful northern European countries have adopted. A new approach also to education is important, giving significance to the students' interactive and networking abilities. At the basis of this build-up there is organizational and social trust.

Universities provide some of the fundamental ingredients, including education, research, expertise and advice. This role requires that universities, based on their academic autonomy and intellectual freedom, are in tune with and open to contribute to local processes and problems, thus reaching economic relevance. The features and problems of the territory that surrounds universities should in a sense provide the starting elements for problem solving processes and the testing ground for solutions in which universities should have the intellectually and scientifically leading role.

Looking at the present European situation two modes and strategies of interaction among the components of the process are worth considering which refer to regions and states alike. The discriminating factor is the way in which member countries and territories pursue competitiveness. One strategy is prevalent in Southern Europe and is based on cost-cutting strategy as envisaged in the European Competitiveness Pact of 2011. The stabilization policies that the European Union imposed upon financially unbalanced countries such as Greece, Spain, Portugal and Italy strengthen this approach. While competition through lower tax rates must wait for more favorable times, this strategy foresees that states and regions gain competitiveness by decreasing wages and weakening welfare. Regions may add additional support to this strategy in the form of looser regulation, exemption from local taxation, and easier access to land and natural resources for potential investors. This strategy can hardly be defined as innovative and sees the specialization of countries in mature and traditional industries where competitiveness through cutting costs may compensate for the lack of innovation and higher productivity up to a point. Consequently the role of universities is more that of an advisor to cost cutting and less that of a producer of knowledge and even an educator. 
Cheaper labor means indeed lower demand for highly educated people and lower return to human capital.

The Lisbon Strategy offered, perhaps in a naïve form, a different, much better strategy based on the investment in nations and regions alike in knowledge infrastructure and human resources. Also important in the strategy is the goal of offering high quality services that are considered to support investment and attract resources. This strategy appears much sounder and sustainable than the former both because it is more in line with the level of income and quality of life that European countries have and because it places the attention and the priority on assets that are scarcely mobile and better linked to territories. Thus it offers a stable and socially sustainable strategy, although not an easy one, that relies on positive incentives and the mobilization of the most productive resources of a society: knowledge and participation. A disadvantage of this strategy is the longer time required to bring results. It may also be difficult to implement in macro-economically unbalanced countries. Yet its consequences are permanent and sound. Northern European countries have relied primarily on this strategy and the results speak by themselves.

This latter strategy is the only advantageous one for territories. Sciencebased knowledge is certainly important and necessary for economic activity, but is far from being sufficient. Other aspects are also fundamental: high level education, in particular, generates the actors (persons and organizations) who are called to absorb, make use of, adapt and improve upon that knowledge. It is also worth stressing that even science-based knowledge is linked to the territories for two reasons. First, it is produced by universities, research centres and enterprises which produce it also by making use of the particular endowments of the territories where they are located. Second, science-based knowledge is never self-sufficient for production and must be adapted to local features and those of specific enterprises.

Competitive success requires that science-based knowledge is complemented by other types of knowledge, having largely tacit nature. This is learning by doing, using, and interacting. This type of knowledge is embedded in social and economic contexts and rooted in organizations and in people who are in turn linked to particular localities. Case-based studies provide ample evidence of the importance of the context and the insufficiency of science to lead to innovation. Moreover, simple observation is sufficient to assess that territories having higher costs may be more competitive than those having lower costs and provide consequently better conditions and opportunities for firms. This fact can be explained by the virtuous interaction of science-based knowledge, tacit knowledge, and the social features of territories and organizations. 


\section{LOCALIZED KNOWLEDGE AND LEARNING REGIONS}

The locally-based role of universities in economic and social development is analysed in different ways in the literature. Three are the traditional perspectives: within the concept of national and regional systems of innovation; the triple helix of industry, government and university; and finally the entrepreneurial university. Although there are various and substantial differences among these three perspectives, all share the view that universities are a fundamental component of a broader economic and social system and that universities are necessary for that system to be successful. Universities should be suppliers of important functions for the success and competitiveness of territories and should be at the same time recipients of demands, needs, and problems coming from industry, governments, and the society, that they try to answer and solve.

The literature on learning regions (Asheim and Parrilli 2012a) seems to be more apt to understand the challenge that European regions are meeting. In fact, it highlights the conditions and forms for the virtuous interaction among governments (governance), firms and organizations (production), universities and research centers (knowledge) in creating and supporting the innovation, competitiveness and welfare of regions. This approach sees innovation as the outcome of processes and interactions that go beyond the three actors constituting the triple helix (universities, governments, and enterprises) and also considers the context and the process through which they operate and interact.

According to the literature on learning regions and while the national and international levels are important and highly significant in favoring/ disfavoring economic dynamism and growth, it is particularly on regional level that those innovative forms of economic action emerge that make economies expand and thrive. In this frame regional advantage has to be based on the endogenous capabilities of regions and their governments, firms and universities rather than only on largely exogenous R\&D efforts. The aim of regional innovation policies should consequently be one of fostering creative knowledge and learning environment which contribute to establish the necessary social and regional economic system. The latter forms the context that supports the pursue of security and flexibility as the necessary bases for knowledge production and learning.

The central role of localized knowledge in the learning regions approach descends from three factors (Lundvall 2012, Lundvall and Lorenz 2012): a) knowledge resides in individuals in the form of tacit knowledge and thus is rather sticky. The stickiness of knowledge can only be decreased, 
but not overcome through the mobility of individuals with scarce talents and skills; b) knowledge is also embedded in organizations and attracting firms plays an important role in the transfer and diffusion of knowledge at local level. However, the effect depends upon the absorptive capacity of the local innovation system; c) such absorptive capacity is made of knowledge embedded in the relationships between individuals and organizations. It includes shared specialized codes of communication and shared norms and common understandings of how to do business, it is often industry and cluster-specific, and reflects the specialization of a region.

According to this view of knowledge-led local development building regional competitive advantage requires a twofold strategy. Close interaction and a common understanding among regional agents should be encouraged to promote learning and adaptability. Along with this, a certain degree of openness, diversity, and even internal contradiction is required to move away from regional routines when it reaches maturity and is threatened by stagnation. In particular, investing broadly in human skills and delegating responsibility to employees should complement attracting top-level scientists and experts.

Within this perspective, broad-based innovation policies need to foster regional innovation systems based on infrastructure for knowledge elaboration, interpretation, and diffusion which is able to combine persons and organizations with different features and playing different economic and social roles. These actors represent different but potentially complementary internal and external knowledge production, interpretation, and diffusion processes. In this perspective learning regions require partnership among governments, business and universities aiming at learning-based processes of innovation and change.

There is agreement among scholars and experts that in rich countries the way based on innovation is the only strategy compatible with their level of development, the level of personal incomes and human capital. However, there is much less agreement on how concretely that strategy can be pursued. The traditional view that such innovation should be pursued by promoting R\&D intensive industries has not survived the test of time and has met innumerable failures together with successes. Applied research and case studies have revealed that this strategy requires much more and also different ingredients, particularly at regional level. Particularly important among these additional elements that are needed is the activation and use of the particular capabilities that each region has.

As a consequence the strategy cannot be translated into a unique path to development and competitiveness. Rather, this strategy consists of a bundle 
of different steps, each bundle based on and in accordance with the region's capabilities. Since each region and its enterprises have unique capabilities, different bundles of steps and particular solutions can be successful and lead to regional competitiveness. Each regional strategy will represent a variant of the fundamental strategy, each region will set up a different, successful structure and will find a particular niche in the national and international division of labor. The highly differentiated structure of modern production and the prevalence of intra-industrial trade offer the background for the success of bundled strategies while they require differentiated, industry-specific knowledge and specialization (Asheim and Parrilli 2012b, p. 5) As a consequence, no type of knowledge should be considered a priory as superior to other types of knowledge in fostering and supporting economic growth and development and obtain priority support through policies. The effectiveness of a strategy of economic development and competitiveness depends in great part upon the differential advantages of the region under the industrial and knowledge profile, which is strongly linked to the already existing knowledge and industrial bases.

It is important to notice that $R \& D$ basis and strict connection to universities is not sufficient for a strategy to promote innovation and competitiveness. Indeed, the organization of the work and production process and incentives are of the utmost importance. Organizations are required that, together with providing better and more qualified jobs, provide the conditions necessary for learning and innovation and also for fostering and supporting patenting. Providing a broad-based access to sources of knowledge reduces the cognitive distance between actors in the regional innovation systems and increases the absorptive capacity of firms and the economic system.

Looking at the role of universities and science-based industries, it should be noted, following Asheim and Parrilli (2012b), that an excessive focus on this perspective has important disadvantages and cannot serve as a basis for a broad strategy of innovation at regional basis. Indeed, this approach tends to concentrate on emerging industries to the disadvantage of other fields of innovation, including engineering-based industry where innovation tends to be incremental and the important field of cultural industries. Second, the success rate of emerging science based industries is quite low and related policies to support these kinds of industries favor disproportionately large cities and regions and highly educated people, to the disadvantage of the bulk of regions, industries and people. Although important, a strategy based on emerging science-based industries cannot work as a general strategy for the development of regions. And in any case regional industry should pursue the participation in national and international knowledge networks and not be linked only to regional universities. These are universities whose 
influence and dominant contacts are not spread all over the world or at least at continental level, but are limited to a usually sub-national area that may be considered consistent from the academic point of view.

Relevant literature on the importance of the role of universities for innovation tends to stress the role of proximity as an explanation of universities' role. Proximity easies the interdependence among university, firm and government and institutional change that come along both in this interdependence and within each of these actors, two aspects that are at the center of the "triple helix" explanation (Etkowitz 2003, Etkowitz and Leydesdorff 1997). This was not always so. Those industries that now are considered mature, such as steel or automobile, had no particular relation to universities. Also a number of high-tech industries and their localization owe their success to military and other forms of public expenditure and research establishments. The upsurge in universities-industry relation since the 1980s is rather strictly linked to the new high-tech industries, including information technology and biotechnologies. Universities are more generally seen as catalysts of local development even if they are not directly involved in that development.

Proximity promotes the efficiency of the innovation process because it promotes the convergence in missions at different levels: local, regional and national (Charles 2003). Clusters represent the most powerful form of proximity, particularly when they include a university or other organizations producing knowledge. As Porter $(1990,1998)$ stresses, local linkages are a key factor in economic competitiveness. However, subsequent research has challenged this view: “...the impact of universities, many of which will be at regional or local scale, will vary considerably over time, over space between sectors, between firms of different sizes..." (Lawton Smith 2006, p. 2). Moreover, as the European Commission has stressed (EC 2003), another important component along with the university-industry interaction, is the recombination and defragmentation of EU public research, including universities and other parts of the European public research system.

\section{CONCLUSIONS: THE UNEASY SITUATION OF UNIVERSITIES IN THE NEW PARADIGM}

During the last three decades university-industry relationships moved from more general, upstream approaches to more specific, downstream focused approaches in the United States and much of Europe alike. The former is more in tune with what is still considered the traditional public and general role of universities, the latter depicts a situation that can be interpreted as the 
initial stage of the new university: either as a social and economic player or as its degeneration into the direction of commercialization.

This move is in parallel and is complementary to the move in the dominant relationship between universities and industry from large transnational companies and few large and prestigious universities to mostly small and medium size enterprises and regional universities. The move then is from arm-length relations to relations based proximity. This transition is not completely over, but it is clear in many countries and industries.

This move may be beneficial for economies in general and local development in particular, but hides the danger that universities are seen increasingly as a local factor of production and as contexts in which professors and researchers can pursue financial benefits at the expense of their public duties. The danger is real indeed and the move from more general, across-the-board approaches to greater proximity and perhaps commonality of interests can only enlarge it. The danger of universities trying to exploit local governments to their own advantage and local governments and industry trying to interfere in the life of regional universities is real. Yet also opportunities are there and it is in the interest of the parties to assess them properly and try to capture.

What comes out from the experiences reviewed above can be summarized in the following five points. First, research and the education of high quality human capital continue to be fundamental missions of any university. Second, the spread of access to high education has led to the proliferation in the number of universities, most of them with an important regional role. This, together with the increasing cost of research and the difficult financial situation of most governments make perhaps inevitable that universities look for additional external resources by pursuing economic relevance. Third, large corporations are more interested in incremental innovation and rely extensively on their internal laboratories, complementing their activity with extensive networks of universities and research laboratories to acquire knowledge of more general meaning. At the same time, small and medium size enterprises are increasingly active in frontier, risky innovation and are more and more interested in cooperating with universities. Fourth, national governments and supranational institutions as the EU are keen to put their countries in the conditions to compete successfully in the international arena through accelerated and widespread innovation by promoting and supporting, among others, a stricter cooperation among universities and industry. Fifth, local governments have more power and more responsibilities than in the past for the economic activity under their jurisdiction and are interested in promoting similar goals as those of national governments but with the intent to have localized returns. 
On the basis of these conclusions it is important to find solutions that keep and possibly improve the quality of universities and their ability to pursue their classical role. However, it is important also to find new and stronger ways by which universities can pursue their economic interest and, above all, contribute to the regional economies without jeopardizing their traditional role. This requires, among other things, that universities cooperate with governments and industry.

However, this may be insufficient. Most universities are preeminent at regional level where they may have or try to have a nearly monopoly power, particularly in certain contexts with low mobility of students and research contacts or when students and industry meet high costs to pursue different choices. This may have negative consequences for the academic quality, consequences that go well beyond, and perhaps are independent from, the economic interest of universities. A situation like this would go to the disadvantage of universities but also of governments and industry and above all the perspectives of local development.

However, various solutions could counteract these dangers and provide universities with additional resources, contacts and flows of information and knowledge coming from the interaction with industry, and allowing them to play the socially important additional role that comes from economic relevance. At the same time, these solutions could help governments and industry to avoid the danger of closeness and localism and upgrade their capacities and opportunities. I limit myself to a few hints, since a proper consideration of the issue would require a serious study.

Regional universities are often too small to be competitive in different fields and have to specialize, if they want to emerge in the broader context. This may cause other disadvantages and dangers for universities and also the local economy. Setting up and entering interregional but also international networks of universities may strengthen the universities, their role and the returns for the regional economy. It is very important to choose carefully the partners based on their features, e.g. partially complementary features and specializations, and not remain limited to proximity. Networks may be stable and involve the whole of each university, but may also concern particular projects. Hiring external professors and researchers, particularly at international level, may usefully complement networking.

One basic condition is certainly the transparency and broad outreach of competition for academic positions and for research calls. This would contribute to create a high level, sound and resilient internal situation of universities and would help attracting good students. As to university-industry cooperation, although is true that it should be based primarily on proximity 
and stability, in particular in the case of applied research and innovation, this relation may be made open and contestable. For instance, in many cases local governments could support the setting up of an alternative network which could also produce synergies and spillovers for the former. Obviously, this can be done if the cost of the investment is not excessively high.

Governments at any level, including the EU, could play an important role in pushing and supporting universities and industry to go in the right direction. In particular the support that governments may provide in different forms should be conditional upon universities and industry willing to go along the lines exposed above of pursue of their public mission, openness, transparency and contestability. At any stage, the non-bureaucratic assessment of the accountability of universities and industry is fundamental.

The situation that globalization first and the crisis then have created make clear that only universities, industry, and governments prosper that are up to the duty of performing their classical missions in better ways but also are up to the challenge that the new conditions of innovation and competition require. Only this kind of partners is able to lead to sustainable local development and the prosperity of their stakeholders and constituencies alike.

\section{BIBLIOGRAPHY}

Aranguren, Mari José, Miren Larrea and James R. Wilson (2012), 'Academia and public policy: Toward the co-generation of knowledge and learning processes', in Asheim and Parrilli (2012), pp. 275-289

Asheim, Bjørn T. and Mario Davide Parrilli (2012a) (eds.), Interactive Learning for Innovation. A key driver within clusters and innovation systems, Palgrave Macmillan

Asheim, Bjørn T. and Mario Davide Parrilli (2012b), 'Introduction: Learning and interaction - Drivers for innovation in current competitive markets, in Asheim and Parrilli (2012a), pp. 1-29

Becker, Sasha O., Peter H. Egger and Maximilian von Ehrlich (2010), 'Going NUTS: The effect of EU Structural Funds on regional performance', Journal of Public Economics, 94 (9), pp. 578-590

Baldwin, Richard and Charles Wyplosz (2012), The Economics of European Integration, 4th Ed., McGraw-Hill

Charles, D.R. (2003), 'Universities and territorial development: reshaping the territorial role of UK universities', Local Economy, 18 (1), 7-20

EC (2003), Third European Report on S\&T indicators 2003: towards a knowledgebased economy, Luxemburg: Office for Official Publications of the European Communities (www.cordis.lu/indicators/third_report.ktm)

Etzkowitz, H. (2003), "Research groups as "quasi-firms": the invention of the 
entrepreneurial university', Research Policy 32 (1), 109-21

Etzkowitz, H. and L. Leydesdorff (1997) (eds.), Universities and the global knowledge economy: a triple helix of university-industry-government relations, London: Pinter

EU (2012), Innovation Union Scorebord 2011, Brussels: European Union

EU (2013), Innovation Union Scoreboard 2013, Brussels: European Union

Florida, Richard (1995), ‘Toward the Learning Region', Futures, Vol. 27, № 5, pp. 527-536

Florida, Richard (2005a), Cities and the Creative Class, New York: Routledge

Florida, Richard (2005b), The Flight of the Creative Class, New York: Harper Business

Florida, Richard (2006), 'The Flight of the Creative Class', Liberal Education, Summer, pp. 22-29

Florida, Richard, Gary Gates, Brian Knudsen, and Kevin Stolarick (2006), The University and the Creative Economy, http://creativeclass.com/rfcgdb/articles/ univ_creative_economy082406.pdf(downloaded on 26 February 2014)

Forge, Simon, Colin Blackman, Itzhak Goldberg and Federico Biagi (2013), Comparing Innovation Performance in the EU and the USA: Lessond from Three ICT Sub-Sectors, JRC Technical Report, European Union

Geiger, Roger L. and Creso M. Sá (2008), Tapping the riches of science. Universities and the promise of economic growth, Cambridge, Mass.: Harvard University Press

Granovetter, Mark (1973), 'The strength of weak ties', American Journal of Sociology, 78 (6), pp.1360-1380

Hollanders, Hugo, Stefano Tarantola and Aleksander Loschky (2009), Regional Innovation Scorebord 2009, Brussels: Pro Inno Europe - Inno Metrics (http://www. proinno-europe.eu/sites/default/files/page/10/03/RIS_2009-Regional_Innovation_ Scoreboard.pdf downloaded on February 17, 2013)

Jensen, Morten B., Björn Johnson, Edward Lorenz, and Bengt Áke Lundvall (2007), 'Forms of knowledge and modes of innovation', Research Policy, 36, pp. 680-693

Lissowska, Maria (2013), 'Welfare against groeth gains in post-transition countries. What are the consequences for stability?', working paper, Warsaw School of Economics

Langlois, Richard N. (2003), 'The vanishing hand: the changing dynamics of industrial capitalism', Industrial and Corporate Change, 12(2), pp. 351-385

Lawton Smith, Helen (2006, Universities, Innovation, and the Economy, London and New York: Routledge

Lundvall, Bengt-Áke (2012), 'Preface', in Asheim and Parrilli (2012), pp. xi-xii

Lundvall, Bengt-Áke and Edward Lorenz (2012), 'Innovation and competence building in the learning economy: Implications for innovation policy', in Asheim and Parrilli (2012), pp. 33-71

Pavitt, K. (2003), Commentary in A. Geuna and W.E. Steinmueller (eds.), Science and Innovation: Rethinking the Rationales for Funding and Governance, London: Edward Elgar, pp. 89-93

Polverari, Laura and John Bachtler (2005), 'The contribution of European Structural Funds to territorial cohesion', Town Planning Review, 76:1 (http://www.jstor.org/ 
stable/40112628)

Porter, M. (1990), The Competitive Advantage of Nations, London: Macmillan

Porter, M. (1998), 'Clusters and the new economics of competitiveness', Harvard Business Review, 77, 1-10

Sonderman, David (2012), 'Productivity in the Euro Area: Any Sign of Convergence', European Central Bank, 1431 (http://www.ecb.int/pub/pdf/scpwps

Tecu, Isabel (2013), 'The location of industrial innovation: does manufacturing matter?, http://papers.ssrn.com/sol3/papers.cfm?abstract_id=2233366 